\title{
Synthesis of Tantalum Hydride Using Mechanical Milling and Its Characterization by XRD, SEM, and TGA
}

\author{
José Luis Iturbe-García, Beatriz Eugenia López-Muñoz \\ Chemistry Department, National Institute of Nuclear Researches, Ocoyoacac, Mexico \\ Email: joseluis.iturbe@inin.gob.mx
}

Received 10 September 2014; revised 18 October 2014; accepted 5 November 2014

Academic Editor: Mufei Xiao, National Autonomous University of Mexico, Mexico

Copyright (C) 2014 by authors and Scientific Research Publishing Inc.

This work is licensed under the Creative Commons Attribution International License (CC BY). http://creativecommons.org/licenses/by/4.0/

(c) (i) Open Access

\begin{abstract}
In this paper, we report the results obtained from different phases of metal hydrides. The synthesis and characterization of tantalum hydrides were obtained "in situ" during mechanical milling. Elemental Ta with purity of $\mathbf{9 9 . 8 \%}$ was used in this investigation to obtain the hydrides. A highenergy ball milling technique was utilized to prepare hydrogenated phases. Ta hydrides and oxides were formed as function of milling process time. Milling times of 5, 10 and 20 hours were programmed, and the ball-to-powder weight ratio was 10:1. The material was first characterized by scanning electron microscopy (SEM) and X-ray diffraction (XRD). Before and after hydrogenation process the material was also analyzed by TGA. X-ray diffraction analysis demonstrated that only tantalum hydrides ( $\mathrm{Ta}_{2} \mathrm{H}$ and $\mathrm{TaH}_{0.5}$ ) were obtained after $20 \mathrm{~h}$ of milling. We will discuss the effect of the ball-milling process about formation "in situ" of nanometric tantalum hydrides with methanol as a hydrogen source.
\end{abstract}

\section{Keywords}

Nanometric Ta Hydrides, Mechanical Milling, Methanol Dissociation, XRD, TGA, SEM

\section{Introduction}

Diverse methods exist to prepare metallic alloys between them, the mechanical alloying technique is now widely used [1]-[3]. Ball milling can often produce unique and metstable materials that cannot be prepared by conventional techniques as wet chemistry method. The ball milling process presents certain advantages e.g. smaller re- 
strictions with respect to composition and into an experimental technique routinely used in the preparation of metal alloys, nanocrystalline, amorphous, nanocomposites, crystalline and quasicrystalline intermediate phases etc. [3]-[5]. Although the technique has been used quite extensively, at present the process of mechanical alloying is not completely understood. The mechanical alloying through high energy ball milling has been used in the preparation and modification of metal hydrides, and other inorganic solids, while organic compounds have been synthesized, including transition metal complexes in the presence or absence of a suitable solvent [6]. Several compounds have recently been synthesized by ball milling such as alanates [7]-[16], borohydrides [17]-[19]. In many cases, this approach implies by-products formation in the preparation of these materials when metals or intermetallics are combined with chemical reagents containing hydrogenated compounds. On the other hand, there is limited information about the tantalum with hydrogen to form metal hydride; this metal has the ability to react with hydrogen under certain conditions of temperature, pressure, and maximum solubility between these elements in terms of these two parameters. Reference is made about the degassing of hydrogen from tantalum, stability in Ta-H system, and liberation of hydrogen achieved by hot vacuum treatment at $1000^{\circ} \mathrm{C}$ and pressure of $10^{-5} \mathrm{~mm}$ $\mathrm{Hg}$. Also are reported some other physicochemical properties of Ta-H as hardness, mechanical properties, electrical resistance, density, and superconductivity [20]. Some other compounds including Ta metal has been studied between them the preparation of tantalum nanopowders through hydrogen reduction of $\mathrm{TaCl}_{5}$ vapor in a furnace aerosol reactor at different temperature ranges [21]. Tantalum is known to absorb large amounts of hydrogen and other potential uses Tantalum membranes preparation with a thin palladium layer by both electroless plating and cold plasma sputter coating techniques has been reported including the hydrogen permeability of bulk tantalum and tantalum coated with thin films of palladium measured at high temperatures and hydrogen partial pressures [22]. Other studies related to Ta element is about the properties of surface layers formed by exposing samples to air and their disintegration as a function of temperature using thermal desorption spectroscopy of hydrogen in tantalum hydrides [23].The metal-hydrogen system has received considerable attention during the last decades because of their technological applications as well as scientific importance. It has been reported the preparation of monohydride-Ta by heating a mixture of $\mathrm{CaH}_{2}$ and $\mathrm{Ta}_{2} \mathrm{O}_{5}$ to temperature no exceeding $900^{\circ} \mathrm{C}$ and studied different types of hydrides including their crystallography, thermodynamic properties and hysteresis in metal-hydrogen systems of the group $\mathrm{V}$ transition metals ( $\mathrm{Nb}, \mathrm{V}$ and $\mathrm{Ta}$ ) [24]. Metal hydrides have a number of potential uses and offer a series of interesting technical applications. The major challenges related to materials for hydrogen storage can be summarized by the gravimetric and volumetric hydrogen density. In this work, the tantalum hydride phases were obtained "in situ" during mechanical alloying process using methanol as hydrogen source. The material was ball milled for a period of $20 \mathrm{~h}$ or less. The powders were analyzed by XRD, SEM and TGA for phases identification, morphology determination and hydrogen content respectively.

\section{Experimental}

Elemental particles of tantalum with purity of $99.8 \%$ were used in this investigation. The synthesis of Ta hydrides was carried out by mechanical milling with a spex-type high-energy ball mill, which was constructed in our institute. The Ta powder material was then put into a stainless steel vial. Three stainless steel balls of 12.7 $\mathrm{mm}$ in diameter were used for milling, and methanol as process agent control to avoid powder adhesion to the walls of the container and to the milling media. The ball-to-powder weight ratio was 10:1. The material was ball milled for 5 to $20 \mathrm{~h}$, at room temperature in an inert atmosphere. All samples were handled without exposure to air in a small lucite glove box under argon gas. To monitor possible change in the Ta element, a small amount of the ball-milled material was intermittently removed from the stainless steel vial at time intervals of 5, 10 and 20 h. From a series of experiments, it was found that these time periods were the most appropriate for examining the possible hydrides formation. The structural evolution during milling was detected by X-ray diffraction analysis in a Siemens D5000 diffractometer that was adapted to an X-ray tube with a copper anode to identify the phases formed. The measurements were taken at a power of $40 \mathrm{kV}, 45 \mathrm{~mA}$. A diffracting beam monocromator and $\mathrm{Cu} \mathrm{K} \alpha$ radiation was used in the same system. The material was placed on portable samples with an angular scanning interval from $20^{\circ}$ to $120^{\circ}$ in $2 \theta$. A scanning electron microscope (JEOL $5900 \mathrm{LV}$ ) equipped with an energy dispersive microanalysis by X-ray (EDAX) system was used to determine the morphology and the chemical composition of the powders. The material was analyzed after $20 \mathrm{~h}$ of milling by thermogravimetric analysis both before and after the hydrogenation process using thermoanalyzer equipment (TA Instruments model TGA-51) that had been previously calibrated. The heating system was programmed from ambient tem- 
perature to $500^{\circ} \mathrm{C}$ at a rate of $10^{\circ} \mathrm{C} / \mathrm{min}$, with nitrogen gas as carrier (high purity $\mathrm{N}_{2}$ ).

\section{Results and Discussion}

Figure 1 shows a micrograph of Ta element utilized in this investigation. The micrograph corresponds to Ta particles; according to the SEM analysis, the scale reported indicated that the particle sizes were larger than 100 microns and possessed a heterogeneous morphology because we started from blades, which were roughly shaped with a lime before the mechanical milling process. The image of the particles was obtained at 100×. According to the results by EDAX for elemental composition, only tantalum was identified without any impurity. Generally, the material must be reduced in size to nanometer scale in which the probability of reacting with hydrogen increases.

Figure 2 shows two micrographs of Ta powder after $20 \mathrm{~h}$ of milling. The image A was obtained at $500 \times$ which represents the material which is distributed in general. A large difference in particle size and morphology is observed after milling because a submicron scale was achieved, and agglomerate accumulation was almost uniformly distributed. Nanometer sizes were obtained when less powder material was milled with the time intervals used in this research. Image B represents the material in detail, it can see a group of clusters formed by particles whose size is of nanometer order, and with the milling time used to reduce its size is supposed that the powders observed on the images corresponding to the tantalum hydrides, since according to XRD diffractograms only hydride phases were identified. The image was obtained at 30,000×.

Figure 3 shown two diffraction patterns corresponding to some Ta phases after 5 hours of milling. The first spectrum at the bottom of the figure corresponds to elemental tantalum, and the peaks indicate that the particle size agrees with that shown in Figure 1 prior to milling. Likewise, using the 00-004-0788 JCPDS card, the material was identified as only containing elemental tantalum.

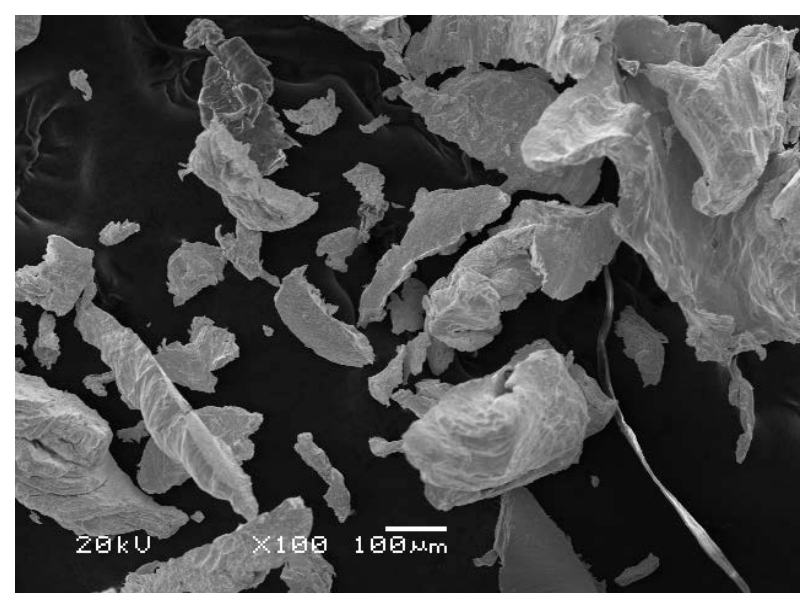

Figure 1. Micrograph of tantalum particles prior to mechanical milling process.

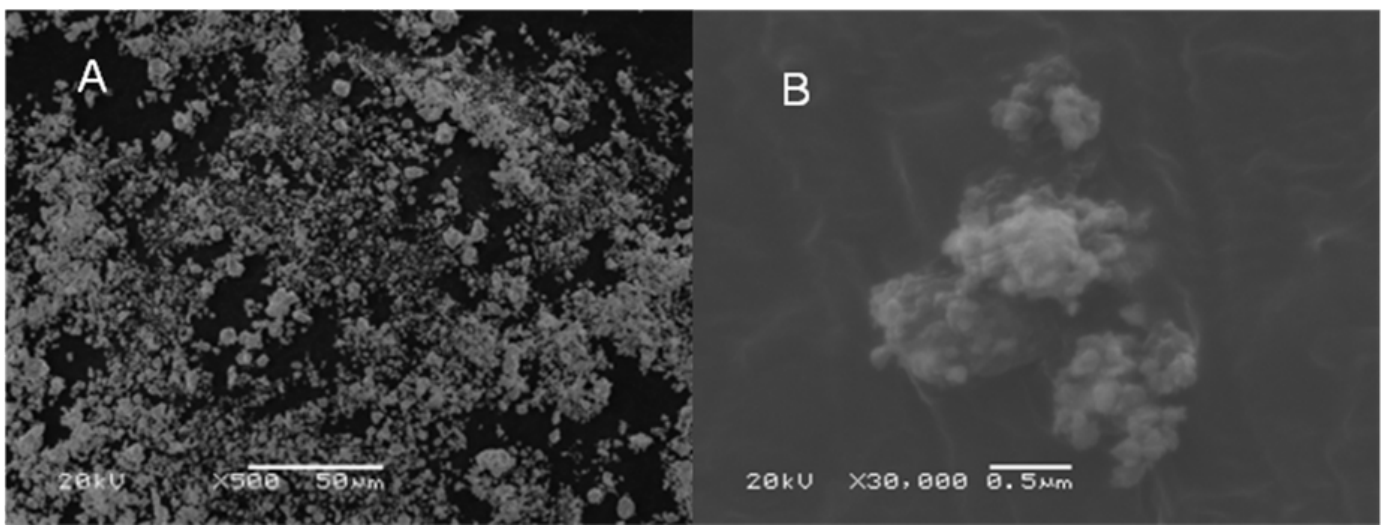

Figure 2. Micrographs of Ta hydride powder after 20 hours of milling. 


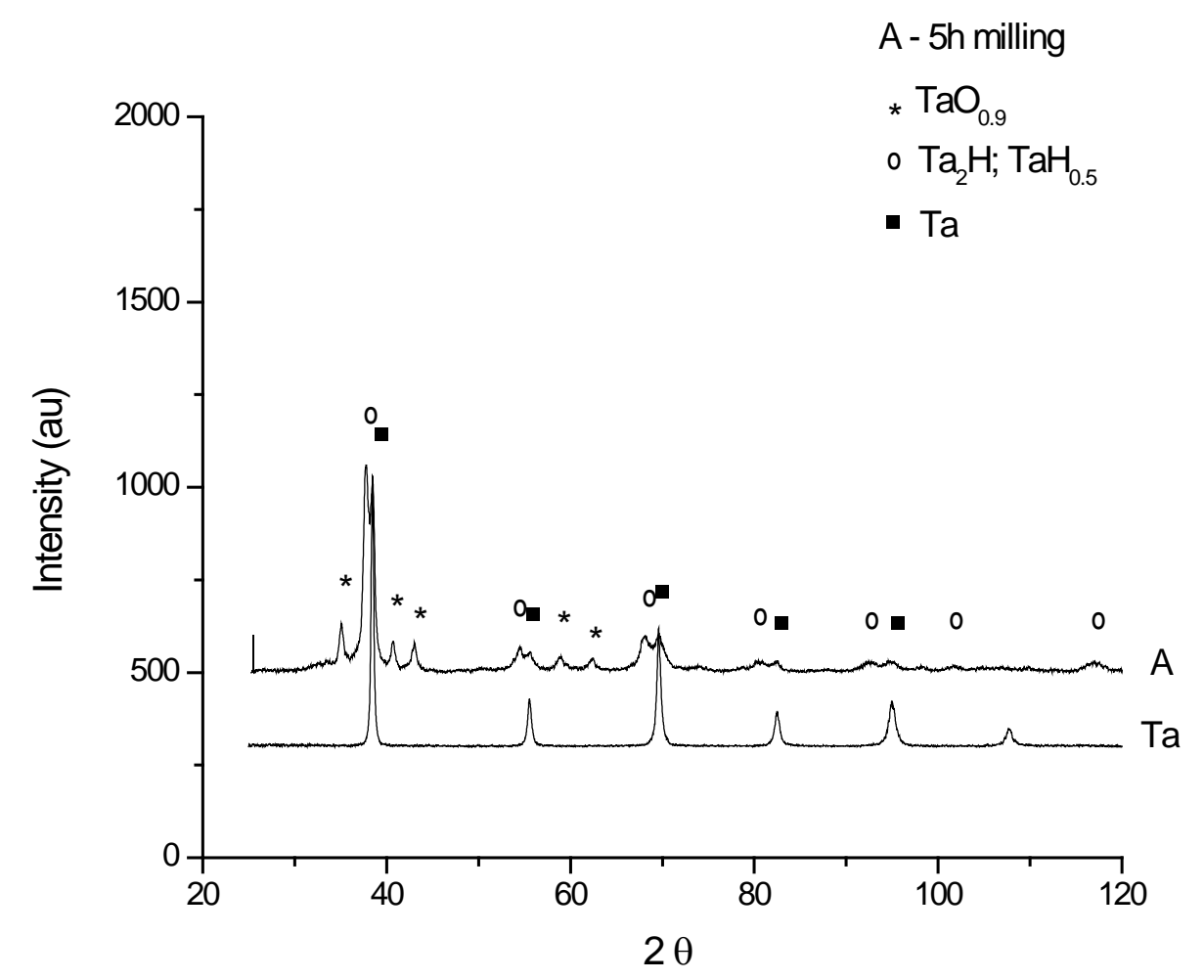

Figure 3. The X-ray diffraction patterns of elemental Ta before and after $5 \mathrm{~h}$ of milling. The figure shows the spectra of Ta, as well as different phases (A) of oxides and hydrides formed at this milling time.

The most intense line for $2 \theta$ occurred at 38.463 degrees. The remaining five peaks were perfectly separated at high angle values. Spectrum A corresponds to material milled 5 hours in which the peaks indicate that tantalum hydrides are formed "in situ" during the milling process. At this time, the reaction result to be incomplete, reaching only an intermediate product, or progressing only through part of the powder charge. Some reaction may take place gradually after the milling time is prolonged. The first phases of tantalum hydrides $\left(\mathrm{Ta}_{2} \mathrm{H}\right.$ and $\left.\mathrm{TaH}_{0.5}\right)$, as well as tantalum oxide phases $\left(\mathrm{TaO}_{0.9}\right)$ were formed, which were identified with JCPDS cards 01-089-4074, 00-032-1281 and 03-065-7449, respectively. Elemental tantalum was evenly dispersed and did not react completely after 5 hours of milling. The formation of hydrides "in situ" may be due to the high impact energy generated in the system between the stainless steel balls, balls-internal surface container, and the material (Ta and methanol). In such circumstances, the milling also reaches high temperatures at the atomic level, which the conditions are created internally causes the dissociation of solvent into its elementary components. Interestingly, the sequence of formation of the tantalum hydride phases during the milling process occurs over a short time ( $5 \mathrm{~h}$ ), and Ta oxides as well tantalum metal unreacted were obtained, possibly because the temperature inside the system at short milling times was not high enough to completely dissociate the methanol. Under these milling conditions, it is assumed that tantalum element react with hydrogen so as with oxygen and possibly increasing the milling time is preferably to react with hydrogen, because as shown in the diffraction pattern, the hydride phases appeared with greater intensity than those of the oxides. On the other hand, the diffraction pattern results at 10 hours of milling, different phases were also observed: hydrides, and oxides (spectrum not presented). In addition, elemental tantalum was not detected, and hydride phases $\left(\mathrm{Ta}_{2} \mathrm{H}, \mathrm{TaH}_{0.5}\right)$ appeared with greater intensity on the diffractogram. According to the JCPDS cards 00-005-01315, tantalum oxide $\left(\mathrm{Ta}_{2} \mathrm{O}_{5}\right)$ was formed instead of the oxide obtained at $5 \mathrm{~h}\left(\mathrm{TaO}_{0.9}\right)$. It is assumed that after 10 hours of milling tantalum has been completely reacted to form the different phases (hydrides and oxide).

Figure 4 shows the diffraction spectrum of the hydride phases 20 hours after milling, in which only the tantalum hydride phases were identified and synthesized "in situ". All deflections of the spectrum were obtained and correspond to different tantalum hydrides phases $\left(\mathrm{Ta}_{2} \mathrm{H}\right.$ and $\left.\mathrm{TaH}_{0.5}\right)$. The spectrum clearly shows that the intensities of the main tantalum hydrides at the $2 \theta$ angle did not interfere with the elemental tantalum intensities, 


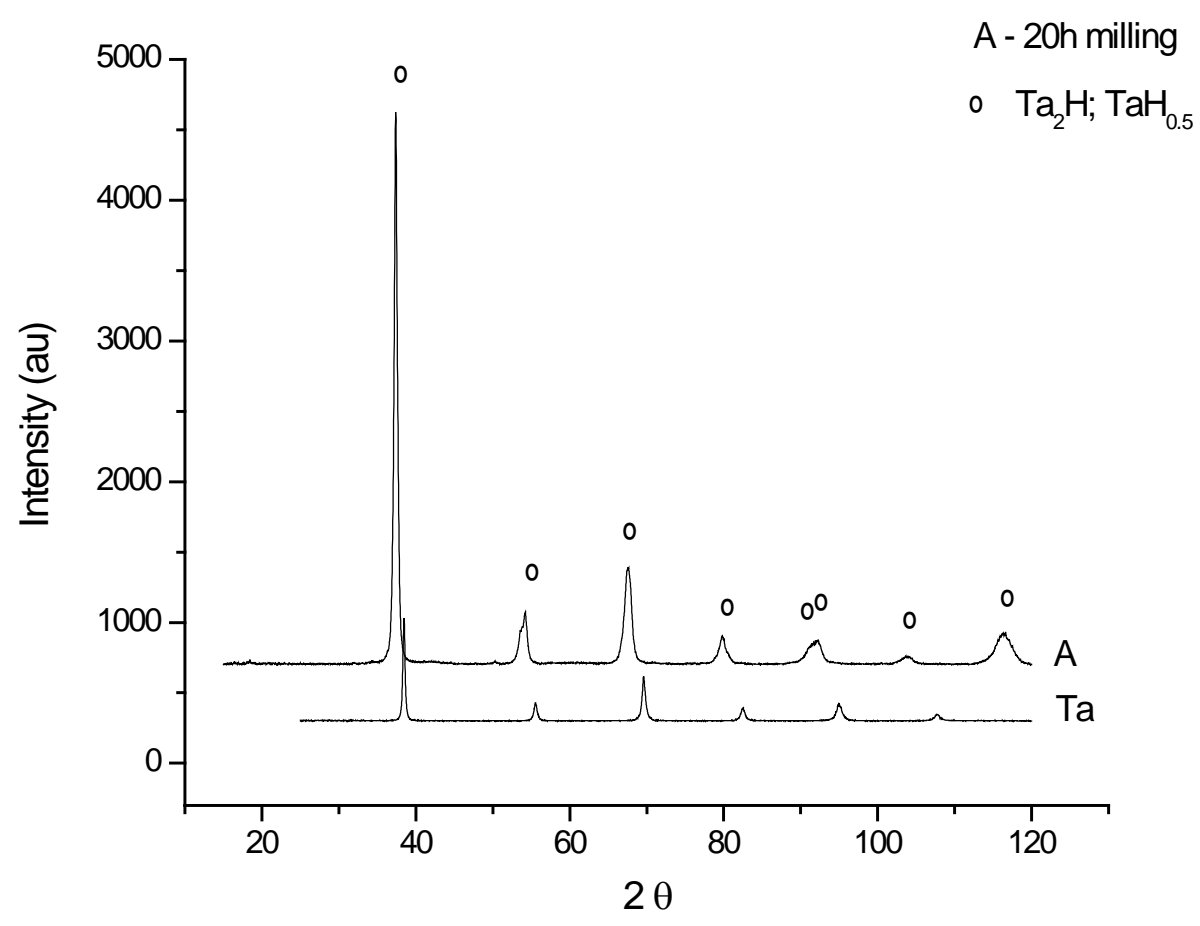

Figure 4. XRD pattern of elemental Ta before milling, and the spectrum showing the tantalum phases formed after $20 \mathrm{~h}$ of milling (A) in which only tantalum hydrides were observed.

whose values are 37.762, and 38.463, respectively. It is possible that the effect of hydrogen and the thermal activation carried out inside the container transformed the material from a nanocrystalline state back to an partial amorphous state and that the hydrogenated phases were formed simultaneously. The results of diffraction showed only tantalum hydrides phases, however, it is possible that tantalum oxides are mixed into the main matrix at low concentrations such that diffraction technique can not detect them because there is a limit of detection in order to show the deflections in this case the corresponding oxides. The sample was also examined by X-ray diffraction at a milling time of 30 hours. The same phases of tantalum hydrides were conserved at this long milling time (30 h). Finally, at $20 \mathrm{~h}$ of milling or less, only tantalum hydrides phases were obtained. During the mechanical milling process, high energy is generated by the intense impact between the container walls, milling media and material. The experimental conditions were created (pressure and temperature) to break the chemical bonds of methanol, which is used as a control medium and dissociates into hydrogen, carbon and oxygen. The bonding energies between carbon-hydrogen, oxygen-hydrogen, and carbon-oxygen are 415, 460 and $352 \mathrm{~kJ} / \mathrm{mol}$, respectively. It should be mentioned that the values are mean energies because the energy of a given bond depends slightly on the other atoms bonded in a given compound. Although, it is very difficult to measure the local microscopic temperature during milling because of the dynamic nature of the milling process, it is assumed that the temperature in the milling system is higher than the binding energy of the methanol solvent. To dissociate into elemental oxygen, hydrogen and carbon, oxygen and hydrogen most likely remain as negative ions $\left(\mathrm{O}^{-}, \mathrm{H}^{-}\right)$, which react quickly with the tantalum. The carbon probably remains in the elemental form and mixes with the other compounds without reacting with Ta or oxides, and carbon's concentration is below the detection limit. Under these experimental conditions, hydride formation may be possible because elemental Ta, as well as the compounds subsequently formed during milling, act as catalysts that improve the reaction conditions, thereby causing dissociation of the control medium into its components, $\mathrm{H}, \mathrm{O}$ and $\mathrm{C}$. Another possibility for the formation of different phases of tantalum may be the reduction in particle size as a function of the milling time. Smaller particle sizes most likely facilitate the formation of tantalum hydrides, as shown in the diffractograms. However, this phenomenon could result from a combination of different events that occur during the milling process and methanol dissociation including high pressure originated between two colliding balls or a ball and the wall of the vial. On the other hand, the hydrogen content up to $2 \mathrm{wt} \%$ was measured in the tantalum hydride phases. It is interesting to note that, in this investigation, the hydrogen absorption process was realized "in situ" 
during over a short milling time. By varying the milling time, different phases of tantalum oxide were formed and changed after $20 \mathrm{~h}$ or less of milling. It is also interesting to note that there is an alternative method for preparing some metal hydrides at low temperatures and normal pressures, which simultaneously confers a source of hydrogen via conversion of methanol or another solvent during mechanical milling process.

Figure 5 shows the thermogram of Ta powder hydrogenated from mechanical milling process. The spectrum corresponds to hydrogen desorption from the material after 20 hours of milling. The hydrogen in the structure of the tantalum material was reacted "in situ" during milling. Hydrogen liberation occurs from room temperature to $330^{\circ} \mathrm{C}$ approximately. It is possible that there is a correlation between the two mass losses on the thermogram curve and hydride phases identified, unfortunately at this time we can not know which of the two hydrides are desorbed at low temperature. The shape of the curve implies that hydrogen diffuse with increasing temperature, the first desortion ramp was realized between $20^{\circ} \mathrm{C}$ (ambient temperature) and $250^{\circ} \mathrm{C}$, the second hydrogen desorption event occurred between $250^{\circ} \mathrm{C}$ and $330^{\circ} \mathrm{C}$. The percentage obtained directly in the thermogram corresponded to the hydrogen that was liberated by the tantalum hydride materials, which was $2.35 \%$ by weight. Furthermore, at a higher temperature of approximately $330^{\circ} \mathrm{C}$, we suppose that at this point of temperature the Ta element is recycled. On the other hand, at these conditions hydrogen is released according to thermogram and after the material increased in weight and moves to the top. In the TGA system the Ta element begin to react with oxygen and tantalum oxide $\left(\mathrm{Ta}_{2} \mathrm{O}_{5}\right)$ was formed. The reaction takes place with oxygen, which is an impurity in nitrogen used as carrier gas into the TGA system, and the chemical reaction was carried out according the equation: $2 \mathrm{Ta}+2.5 \mathrm{O}_{2} \stackrel{\Delta}{\longrightarrow} \mathrm{Ta}_{2} \mathrm{O}_{5}$. By XRD tantalum phase was identified without any other impurity which is illustrated in the Figure 5(B). On the other hand, under these experimental conditions, with $20 \mathrm{~h}$ of milling process used in this work, Ta hydrides were obtained. Based on these results, it can be confirmed that the hydride phases of tantalum were formed "in situ" during the milling process. The mechanical milling system has proven to be a useful tool for preparation of some hydrides materials as well as for the investigation of chemical transformations that can take place in some compounds under a solvent appropriate condition into the vial. When preparing intermetallic, alloys or metal hydrides each case is different according to the type of research that wants to perform, since each mechanical milling system are different. It is possible that the start of milling a thermal activation can be originated creating the conditions to dissociate the solvent and the same time reduction in particulate matter and therefore different chemical reactions and structural changes take place as a function of milling time perhaps this process be done instantly. In this case, we believe that no pressure is produced within the vial due to genera-

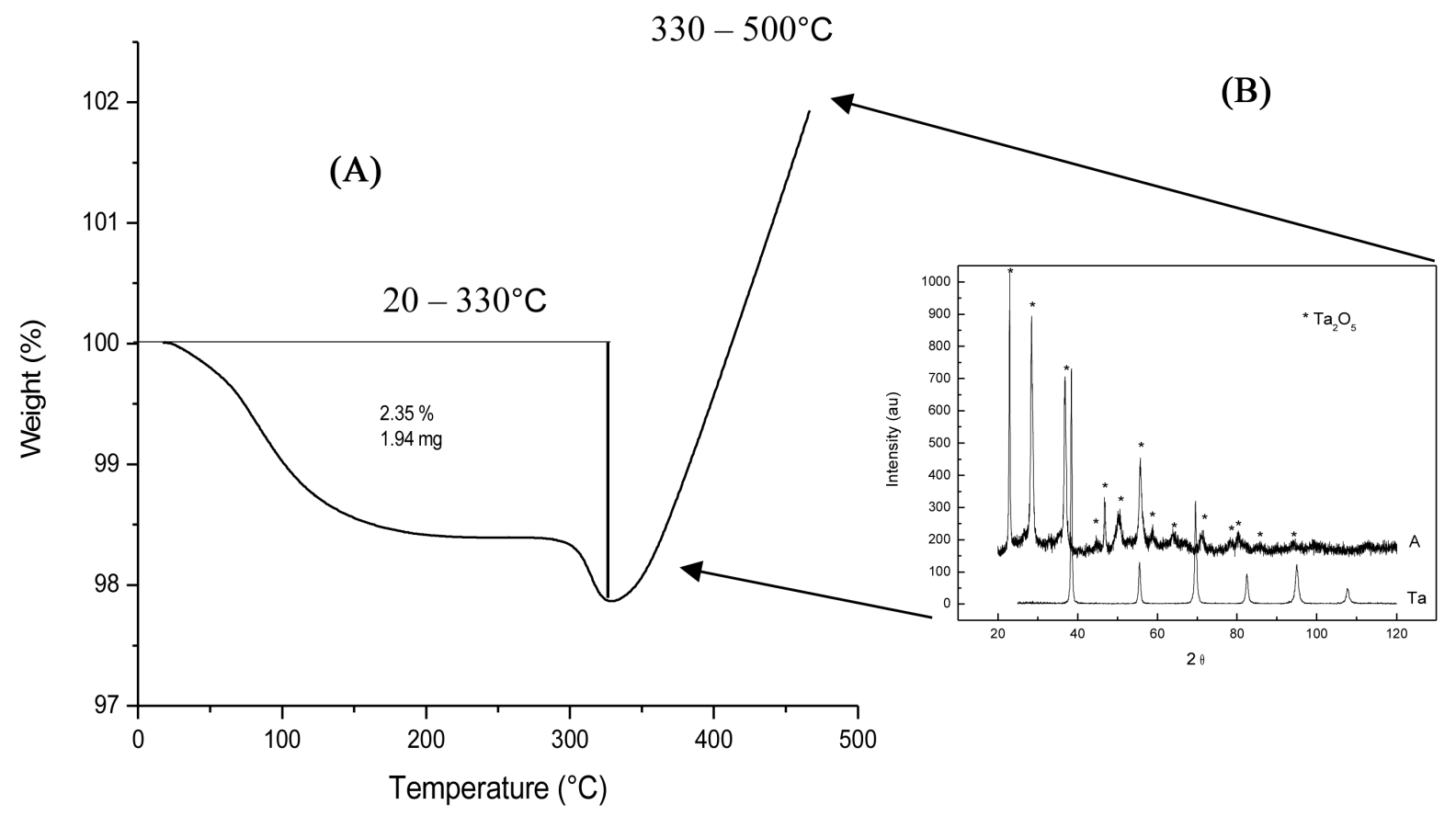

Figure 5. Thermogram of Ta after $20 \mathrm{~h}$ of milling process, indicating hydrogen liberation as a function of temperature (A) and XRD pattern (B) of $\mathrm{Ta}_{2} \mathrm{O}_{5}$ formation as by product after hydrogen desorption. 
tion of hydrogen, oxygen and temperature, since the gases react as they are being produced during the milling time and temperature is dissipated as heat to the exterior through the container walls. Hydrogen storage in solid materials is the long-term goal in hydrogen technology. During the last two decades, a number of promising new lightweight materials have been developed and studied. However, no materials satisfying each of the main targets with respect to storage capacities thermodynamics and kinetics have been found, and further research in this field is required. These efforts will involve combinations of theory and experiments, development and improvement of novel methods for synthesis and finally, "in situ" methods and the development of strategies that combine different preparation techniques. Many research efforts are currently under way to develop new technologies for hydrogen storage. Metal hydrides are attractive candidates for a safe way to store hydrogen for a broad range of practical purposes, such as portable, mobile or static applications. However, more research is needed to develop metal hydrides that meet all industry requirements.

\section{Conclusion}

In conclusion, the tantalum hydrides were formed "in situ" during the mechanical milling process. Due to the high impact energy process within the mechanical milling system, the internal conditions into the sealed vial were created and methanol used as control agent was dissociated in carbon, hydrogen and oxygen. The oxygen and hydrogen were reacted with tantalum for producing the corresponding oxide and hydride phases, respectively after 5 to $20 \mathrm{~h}$ of milling. According to the SEM analysis tantalum hydride at nanometric particle sizes were obtained. Although the exact mechanism of milling phenomena should be determined on a case-by-case basis depending of the type of ball mill used, it appears that mechanical milling processes in tantalum powder was primarily driven by structural changes and high pressure and temperature by the components into the sealed vial during milling. The mechanical milling process can be used as an alternative method for some nanometric hydride preparations such as the tantalum hydride phases which were reproducible and readily formed. The TGA results, in the temperature interval programmed the percentage of hydrogen released was $2.1 \pm 0.5$ by weight.

\section{Acknowledgements}

We would like to thank the personnel of the scanning electron microscope, X-ray diffraction machine, and thermogravimetric analysis for their valuable support.

\section{References}

[1] Gutfleisch, O., Dal Toè, S., Herrich, M., Handstein, A. and Pratt, A. (2005) Hydrogen Sorption Properties of Mg-1 wt.\% Ni-0.2 wt.\% Pd Prepared by Reactive Milling. Journal of Alloys and Compounds, 404-406, 413-416. http://dx.doi.org/10.1016/j.jallcom.2004.09.083

[2] Yoonyoung, K., Eung-Kyu, L., Jae-Hyeok, S., Young, W.C. and Kyung, B.Y. (2006) Mechanochemical Synthesis and Thermal Descomposition of $\mathrm{Mg}\left(\mathrm{AlH}_{4}\right)_{2}$. Journal of Alloys and Compounds, 422, 283-287. http://dx.doi.org/10.1016/j.jallcom.2005.11.063

[3] Suryanarayana, C. (2001) Mechanical Alloying and Milling. Progress in Materials Science, 46, 1-184. http://dx.doi.org/10.1016/S0079-6425(99)00010-9

[4] Gross, K.J., Chartouni, D., Leroy, E., Zuttel, A. and Schlapbach, L. (1998) Mechanically Milled Mg Composites for Hydrogen Storage: The Relationship between Morphology and Kinetics. Journal of Alloys and Compounds, 259-270.

[5] Fecht, H.J., Hellstern, E., Fu, Z. and Johnson, W.L. (1990) Nanocrystalline Metals Prepared by High-Energy Ball Milling. Metallurgical and Materials Transactions A, 21, 2333-2337. http://dx.doi.org/10.1007/BF02646980

[6] Balema, V.P., Wiench, J.W., Pruski, M. and Pecharsky, V.K. (2002) Mechanically Induced Solid-State Generation of Phosphorus Ylides and the Solvent-Free Wittig Reaction. Journal of the American Chemical Society, 124, 6244-6245. http://dx.doi.org/10.1021/ja017908p

[7] Mamatha, M., Weidenthaler, C., Pommerin, A., Felderhoff, M. and Schüth, F. (2006) Comparative Studies of the Decomposition of Alanates Followed by in Situ XRD and DSC Methods. Journal of Alloys and Compounds, 416, 303314. http://dx.doi.org/10.1016/j.jallcom.2005.09.004

[8] Mamatha, M., Bogdanović, B., Felderhoff, M., Pommerin, A., Schmidt, W. and Schüth, F. (2006) Mechanochemical Preparation and Investigation of Properties of Magnesium, Calcium and Lithium-Magnesium Alanates. Journal of Alloys and Compounds, 407, 78-86. http://dx.doi.org/10.1016/j.jallcom.2005.06.069 


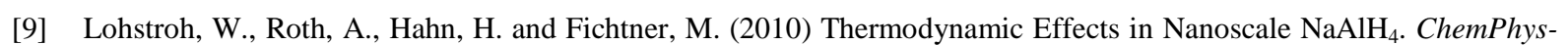
Chem, 11, 789-792. http://dx.doi.org/10.1002/cphc.200900767

[10] Balema, V.P. and Balema, L. (2005) Missing Pieces of the Puzzle or about Some Unresolved Issues in Solid State Chemistry of Alkali Metal Aluminohydrides. Physical Chemistry Chemical Physics, 7, 1310-1314. http://dx.doi.org/10.1039/b419490j

[11] Chaudhuri, S., Graetz, J., Ignatov, A., Reilly, J.J. and Muckerman, J.T. (2006) Understanding the Role of Ti in Reversible Hydrogen Storage as Sodium Alanate: A Combined Experimental and Density Functional Theoretical Approach. Journal of the American Chemical Society, 128, 11404-11415. http://dx.doi.org/10.1021/ja060437s

[12] Von Colbe, J.M.B., Felderhoff, M., Bogdanovic, B., Schüth, F. and Weidenthaler, C. (2005) One-Step Direct Synthesis of a Ti-Doped Sodium Alanate Hydrogen Storage Material. Chemical Communications, 4732-4734. http://dx.doi.org/10.1039/b506502j

[13] Huot, J., Boily, S., Guther, V. and Schulz, R. (1999) Synthesis of $\mathrm{Na}_{3} \mathrm{AlH}_{6}$ and $\mathrm{Na}_{2} \mathrm{LiAlH}_{6}$ by Mechanical Alloying. Journal of Alloys and Compounds, 383, 304-306. http://dx.doi.org/10.1016/S0925-8388(98)00875-5

[14] Kojima, Y., Kawai, Y., Hagab, T., Matsumoto, M. and Koiwai, A. (2007) Direct Formation of LiAlH 4 by a Mechanochemical Reaction. Journal of Alloys and Compounds, 441, 189-191. http://dx.doi.org/10.1016/j.jallcom.2006.08.343

[15] Balema, V.P., Pecharsky, V.K. and Dennis, K.W. (2000) Solid State Phase Transformations in LiAlH $_{4}$ during HighEnergy Ball-Milling. Journal of Alloys and Compounds, 313, 69-74. http://dx.doi.org/10.1016/S0925-8388(00)01201-9

[16] Mamatha, M., Bogdanovic, B., Felderhoff, M., Pommerin, A., Schmidt, W., Schuth, F. and Weidenthaler, C. (2006) Mechanochemical Preparation and Investigation of Properties of Magnesium, Calcium and Lithium-Magnesium Alanates. Journal of Alloys and Compounds, 407, 78-86. http://dx.doi.org/10.1016/j.jallcom.2005.06.069

[17] Vajo, J.J. and Olson, G.L. (2007) Hydrogen Storage in Destabilized Chemical Systems. Scripta Materialia, 56, 829834. http://dx.doi.org/10.1016/j.scriptamat.2007.01.002

[18] Zhang, Y., Zhang, W.-S., Wang, A.-Q., Sun, L.-X., Fan, M.-Q., Chu, H.-L., Sun, J.-C. and Zhang, T. (2007) LiBH 4 Nanoparticles Supported by Disordered Mesoporous Carbon: Hydrogen Storage Performances and Destabilization Mechanisms. International Journal of Hydrogen Energy, 32, 3976-3980. http://dx.doi.org/10.1016/j.ijhydene.2007.04.010

[19] Liu, B.H. and Li, Z.P. (2009) A Review: Hydrogen Generation from Borohydride Hydrolysis Reaction. Journal of Power Sources, 187, 527-534. http://dx.doi.org/10.1016/j.jpowsour.2008.11.032

[20] Miller, G.L. (1959) Corrosion by Chemicals, Gases and Liquids Metals. In: Finniston, H.M., Ed., Metallurgy of the Rarer Metals-6, Tantalum and Niobium, Butterworths Scientific Publications, London, 431-543.

[21] Park, K.Y., Kim, H.J. and Suh, Y.J. (2007) Preparation of Tantalum Nanopowders through Hydrogen Reduction of $\mathrm{TaCl}_{5}$ Vapor. Powder Technology, 172, 144-148. http://dx.doi.org/10.1016/j.powtec.2006.11.011

[22] Rothenberger, K.S., Howard, B.H., Killmeyer, R.P., Enick, R.M., Bustamante, F., Ciocco, M.V., Morreale, B.D. and Buxbaum, E. (2003) Evaluation of Tantalum-Based Materials for Hydrogen Separation at Elevated Temperatures and Pressures. Journal of Membrane Science, 218, 19-37. http://dx.doi.org/10.1016/S0376-7388(03)00134-0

[23] Porschke, E., Shaltiel, D., Klatt, K.H. and Wenzl, H. (1986) Hydrogen Desorption from Tantalum with Segregated Oxide Surface Layers. Journal of Physics and Chemistry of Solids, 47, 1003-1011. http://dx.doi.org/10.1016/0022-3697(86)90116-2

[24] Esayed, A.Y. and Northwood, D.O. (1992) Metal Hydrides: A Review of Group V Transition Metals-Niobium, Vanadium and Tanalum. International Journal of Hydrogen Energy, 17, 41-52.

http://dx.doi.org/10.1016/0360-3199(92)90220-Q 
Scientific Research Publishing (SCIRP) is one of the largest Open Access journal publishers. It is currently publishing more than 200 open access, online, peer-reviewed journals covering a wide range of academic disciplines. SCIRP serves the worldwide academic communities and contributes to the progress and application of science with its publication.

Other selected journals from SCIRP are listed as below. Submit your manuscript to us via either submit@scirp.org or Online Submission Portal.
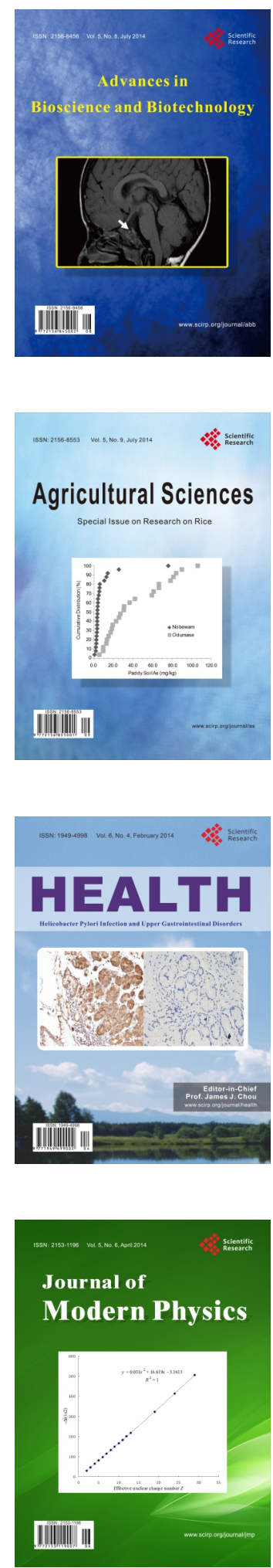
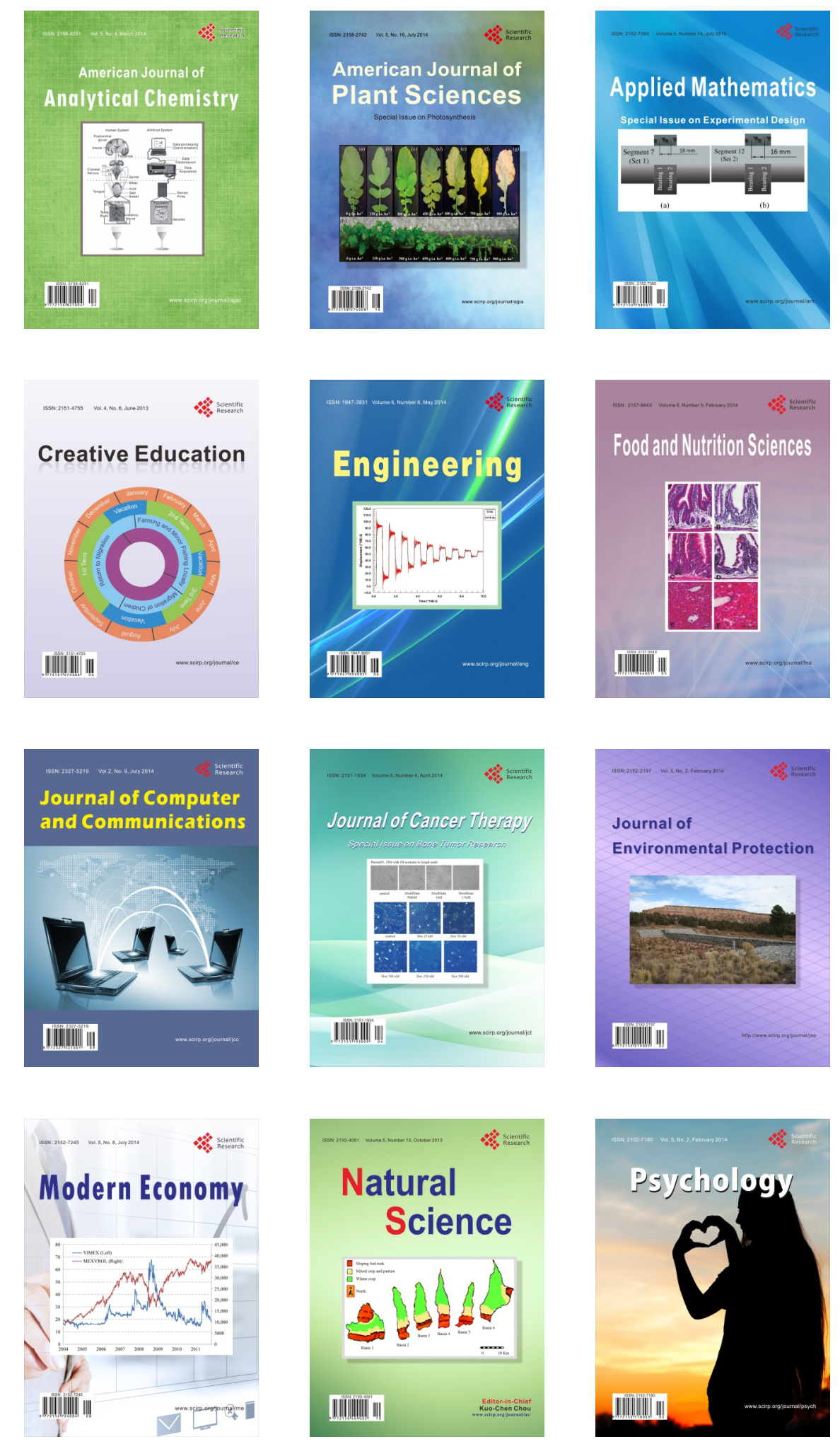